The Review of Finance and Banking

print ISSN 2067-2713, online ISSN 2067-3825

Volume 12, Issue 2, Year 2020

http://dx.doi.org/10.24818/rfb.20.12.02.02, Pages 115-136

\title{
DOES TRADING VOLUME EXPLAIN THE INFORMATION FLOW OF CRUDE PALM OIL FUTURES RETURNS?
}

\author{
YOU-HOW GO AND WEE-YEAP LAU
}

\begin{abstract}
This study examines the role of trading volume in the crude palm oil (CPO) futures market as a proxy for information flow from the perspective of the mixture-ofdistributions hypothesis (MDH). Using the data from January 2000 to April 2017, a symmetric GARCH model has been estimated, in which the residuals follow alternatively the normal Student-t and generalised error distribution. An alternative augmented model that consists of trading volume as an exogenous variable is estimated with the same error distributions. Our results suggest several conclusions: First, the trading volume could not act as a true proxy for information flow. This indicates that volume of futures trading contains relatively less price-sensitive information. Secondly, the inclusion of trading volume into the conditional variance equation with Student-t distributed errors is important for modelling purposes when the returns are leptokurtic and positively skewed. Hence, it can be concluded that the use of return and trading volume will enhance the current information set used by practitioners and analysts in pricing the CPO futures contract when there exists a high degree of leptokurtosis in the returns. This is the first study that validates the MDH in the context of the CPO futures market.
\end{abstract}

\section{INTRODUCTION}

The knowledge of investors' reaction to unobservable information arrival within different financial markets has long been discussed in finance. Several scholars have put forward that trading volume is generally thought to be a proxy for information flow in reflecting market returns and providing a signal of informed trading (Lamoureux and Lastrapes, 1990a; Blume et al., 1994; Hiemstra and Jones, 1994; Suominen, 2001; Le and Zurbruegg, 2010). To forecast the price movement, the explanatory power of trading volume to price variability mainly focused on stocks, which generally can be held over many years to reduce volatility through portfolio diversification. It is different for commodities, where the price is sensitive to global forces of supply, demand and occasional natural disasters that shorten the trading duration. This indirectly increases volatility in commodity markets.

Against these unpredictable phenomena, futures contracts are often used by investors to form expectations not only about fundamental directly but also about market reaction for the delivery of commodities in the future. Furthermore, hedging strategies and risk avoidance through the usage of the futures contract are of great importance, especially during uncertain periods (Go and Lau, 2014; Go and Lau, 2015). The arrival of new information usually causes investors to change their expectations about the future price. However, a change in their belief about the future price does not mirror the information content of news in all cases. To determine

Received by the editors November 27, 2019. Accepted by the editors July 24, 2020.

Keywords: Price-volume relation, Mixture-of-distributions hypothesis, Volatility persistence, Distributional assumptions, Crude palm oil, the Futures market.

JEL Classification: G12, G13, G14.

You-How Go, PhD, Assistant Professor, Department of Economics, Faculty of Business and Finance, Universiti Tunku Abdul Rahman, Malaysia. E-mail: goyh@utar.edu.my.

Wee-Yeap Lau, PhD, Associate Professor, Faculty of Economics and Administration, University of Malaya, Malaysia. E-mail: wylau@um.edu.my.

This paper is in final form and no version of it will be submitted for publication elsewhere. 
whether there is a significant response from the financial markets, trading volume is thought to reflect the differences in price reaction of investors to unexpected events. Hence, trading volume is an important supplement of futures price behaviour when the information flow to the market is continuous. To date, the role of trading volume in transmitting new information flow is still debatable concerning market reaction when the return exhibits asymmetric distribution. In other words, how does the trading volume of commodity futures markets drive information transmission channel of returns that show different degrees of skewed distribution?

One of the ways to tackle the question is to rely upon the inclusion of an essential variable in the conditional variance equation that entails the reduction of volatility persistence. Within the market, the role of trading volume in transmitting information over time is subject to volatility persistence. In that sense, its presence contributes to the reduction of volatility persistence which has been recognised as the arrival of new information. This suggests that trading volume conveys information in prices to reflect the noise movement of prices that cannot be obtained from historical price data itself. Fundamentally, the marked reduction can be explicitly explained by the mixture-of-distributions hypothesis (MDH) that attracts the most attention. This is reflected more in stock markets as commonly thought can provide companies with access to capital in exchange for giving investors a slice of ownership (Clark, 1973; Epps, 1975; Epps and Epps, 1976; Tauchen and Pitts, 1983; Harris, 1987; Lamoureux and Lastrapes, 1990a; Lamoureux and Lastrapes, 1994; Richardson and Smith, 1994; Foster, 1995; Bollerslev and Jubinski, 1999; Lobato and Velasco, 2000; Liesenfeld, 2001; Choi et al., 2012; Carroll and Kearney, 2012).

The study focuses on crude palm oil (CPO) because it currently holds the largest share of the edible oil market in the world. There is an estimated 90 per cent of the total production of $\mathrm{CPO}$ would be allocated for food consumption, whereas the remaining 10 per cent for industrial use such as material in cosmetic or fuel product (Malaysian Palm Oil Board, 2015). Indirectly, any changes of this proportion will lead to a change in futures prices and cause a deviation from the inflationary expectation, and eventually will impact on the food security (Food and Agricultural Organization of the United Nations, 2011).

Our study attempts to make two contributions to the existing literature. First, we focus on the role of trading volume in the process that generates return and volatility in the commodity futures market. Unlike most studies, we emphasize such a role in the context of CPO instead of other non-perishable commodities because market participants normally encounter high perception of risk inherent in buying or selling specific perishable commodities. This usually makes them unable to effectively hedge their own futures positions with CPO futures contracts traded in the exchange. Therefore, from the perspective of $\mathrm{MDH}$, it is worth to validate whether the volume of CPO futures trading can account for the flow of information which is entirely unobservable to market participants.

Second, the contribution that distinguishes our study from others is distributional assumptions in volatility modelling. By considering trading volume, we estimate the model of conditional variance for returns with nesting several well-known error assumptions, namely the normal Student-t and generalised error distributions. This allows us to explore the impact of distributional assumptions on the model fitting process with the presence of trading volume as an exogenous variable. In this regard, we can determine whether incorporating trading volume into the model with a certain distributional assumption can produce unstable and potentially explosive volatility or more reasonable and realistic dynamics for the return.

This study provides an improved understanding in terms of how commodity market participants react to new information arrival which can be explored by separating the sample period into different regimes of returns. On the modelling side, the examination using a model specification based on the normal distribution has become questionable. Notably, the conditional distribution of returns during a specific sub-period often appears to be skewed and contains a persistent amount of leptokurtosis. An incorrect distribution may cause model misspecification and fail to fit a particular stylized fact of returns, leading to sizeable loss of efficiency 
of corresponding parameter estimates. For instance, Agnolucci (2009) finds that the models with non-normal distributions perform better in capturing crude oil volatility than those with a normal distribution.

Returns are asymmetrically distributed, implying the existence of different outlooks among market participants towards the arrival of new information. It has been suggested in the empirical studies that a market tends to have overreaction or/and underreaction to bad or good news (Fama, 1998; Barberis et al., 1998). Two statistical measures can detect the market reaction, one by skewness that captures different attitudes towards bad or good news, the other by kurtosis that captures different levels of overreaction or underreaction. For instance, Do et al. (2014) find that trading volume being a source of heteroscedasticity in asset returns, but it provides a less significant impact on the level of negative skewness of returns.

One empirical phenomenon worth mentioning is that statistical measures can be used to identify regime shifts in higher moments of returns and adequately specify a generalised autoregressive conditional heteroscedasticity $(\mathrm{GARCH})$ model. In specific conditional autoregressive models nesting the GARCH, inconsistent estimators may result from the presence of asymmetric distribution in the conditional error density (Newey and Steigerwald, 1997). Although maximum likelihood estimators are consistent and asymptotically normal under mild conditions, the efficiency of estimators is subject to an error distribution. For instance, theoretical evidence from González-Rivera and Drost (1999) shows that efficiency of maximum likelihood estimators depends on kurtosis and skewness of the conditional error density.

Our study attempts to estimate the conditional variance model for returns with the normal Student-t, and generalised error distributions. Specific properties of GARCH processes can be matched with a particular form of the error distribution to clarify whether a shock in trading volume is persistent in reducing the volatility of returns over time. To measure the influence of trading volume on the volatility of returns, we compare a univariate model that captures the presence of stylized facts in returns against an alternative augmented model that consists of trading volume as an exogenous variable.

Perhaps more importantly, our findings are expected to benefit investors and financial analysts. For investors, they can use knowledge of trading volume for improvement of their shortrun return forecasts if trading volume plays a role of information flow. Since trading volume is thought to be driven by identical factors that generate volatility of returns, it is particularly relevant to technical analysis in providing insights on quality of information contained in price statistics. Thus, this may result in more informed decision making. If the estimates appear to be unbiased in the presence of trading volume, financial analysts can consider incorporating trading volume in the GARCH model for significant improvement of the fit of their model. In order to allow for a leptokurtic and skewed return, an adequate distributional assumption on errors for the model estimation seems to be crucial in improving variance forecasts. There is an important implication for them to manage hedging and trading strategies.

The remaining of this study is organised as follows. Section 2 presents an overview of CPO futures market, followed by the literature review. Section 4 describes the data and methodology. Section 5 discusses the empirical results, and the last section concludes the study.

\section{Overview of CPO Futures Market}

In Malaysia, oil palm is recognised as one of the golden crops that contributes to the development of agricultural sector. With the growing importance of palm oil in the country's economy, the producers need to have stable price for the crop. To guard against the price fluctuation, the CPO futures contract was introduced from October 1980 for hedging purposes. The CPO futures trading facilitates the process of efficient price discovery for producers, suppliers and buyers.

As shown in Table 1, the consumption of palm oil is found to increase from 57.319 million metric tonnes in 2013/14 to 62.9 million metric tonnes in the last five years. In $2017 / 18$, it is 
forecasted that palm oil and palm kernel oil jointly contribute to 70.13 million metric tonnes (37 per cent) of the worldwide consumption of edible oil.

Table 1: Worldwide consumption of edible oil (million metric tonnes), 2013-2018

\begin{tabular}{|l|c|c|c|c|c|}
\hline \multicolumn{7}{|c|}{ Table 1: Worldwide consumption of edible oil } \\
\hline & $2013 / 14$ & $2014 / 15$ & $2015 / 16$ & $2016 / 17$ & $2017 / 18^{*}$ \\
\hline Palm oil & 57.31 & 58.69 & 59.28 & 59.97 & 62.92 \\
\hline Soybean oil & 45.27 & 47.83 & 52.15 & 53.62 & 55.99 \\
\hline Rapeseed oil & 26.17 & 27.29 & 28.18 & 29.22 & 29.35 \\
\hline Sunflower seed oil & 14.14 & 14.11 & 15.18 & 16.52 & 16.79 \\
\hline Palm kernel oil & 6.58 & 7.22 & 6.81 & 7.02 & 7.21 \\
\hline Peanut oil & 5.68 & 5.51 & 5.44 & 5.77 & 5.99 \\
\hline Cottonseed oil & 5.09 & 5.06 & 4.4 & 4.38 & 4.93 \\
\hline Coconut oil & 3.34 & 3.29 & 3.26 & 3.17 & 3.22 \\
\hline Olive oil & 2.97 & 2.64 & 2.81 & 2.63 & 2.64 \\
\hline Note: * denotes forecasted values. \\
\hline Source: Statista (2018).
\end{tabular}

With substantial contribution of palm oil in the global market as compared to other edible oils, the role of information in CPO futures trading is important for the overall smooth functioning of the market. Therefore, this study attempts to investigate the role of information in the CPO futures market empirically.

\section{Literature Review}

The MDH represents an intuitive and appealing explanation for the empirically observed relationship between return and trading volume. Most existing studies provide support on such a hypothesis which suggests that trading volume can serve as a proxy for information flow to reflect the volatility of returns contemporaneously. Many alternative models have been proposed incorporating the leptokurtic feature for returns in explaining the contemporaneous relationship between return and trading volume. In general, the literature takes four lines of explaining how such a relationship depends jointly upon information flow.

The first line originates from Clark (1973) who puts forth the MDH. He states that a stochastic process in price changes allows information to be transmitted simultaneously along with trading volume across any periods. To explain such a process in capturing speculative pressure in the price movement, he develops a subordinated stochastic volatility model with the variance and finds that market returns should be predictable by an unobserved non-constant rate of information arrival. As a result, a high trading volume would increase the variance of price changes.

The second line of the contemporaneous relationship arises not from a common event or a directing variable as information flow, but it is from the existence of heterogeneity of trading behaviour. Epps (1975) examines the price-volume relation under bull and bear markets. If information arrival leaves investors to react differently to market shocks in the subsequent period, it often leads to a partial adjustment in the market price towards the new information. To describe the magnitude of overall price changes due to different levels of disagreement among traders, Epps and Epps (1976) develop an alternative formulation of the equilibrium model of intraday price determination, where price changes follow mixture of distributions and trading volumes act as a mixing variable.

To further support the widespread application of the equilibrium model, Tauchen and Pitts (1983) state that the potential number of information arrivals should be serially uncorrelated with traders' sensitivity to new information. Based on daily data of 1976-1979 for T-bill futures prices, they develop a standard bivariate mixture model, and their model shows that price and trading volume are positively related to the unobservable mixing variable. This indicates that a 
high variance of the daily rate of information flow provides a strong contemporaneous correlation between absolute price changes and trading volumes. From this insight, their model becomes a standard version for the MDH.

By using daily data of IBM and Kodak stocks, Liesenfeld (2001) points out from the estimation results that the short-run volatility dynamics are directed by new arrival process, while the long-run dynamics are associated with traders' sensitivity to the arrival of new information. Due to this, a standard bivariate mixture model should allow the number of information arrivals to be serially correlated with traders' sensitivity to new information. The author takes the leverage effect and different volume-volatility dynamics into account to extend the model to be the generalised mixture model. As compared to the standard model, the author's extended model is found to provide a better explanation for the behaviour of volatility. In the case of the Korean stock market, Choi et al. (2012) use an exponential GARCH model and find that the effect of bad news on return volatility is much more significant than good news. This effect subsequently contributes to a contemporaneous relationship between return and trading volume during 2000-2010.

The third line that concerns the joint time-series behaviour of return and volume volatilities is the explanatory power of trading activities on return volatility. The work by Lamoureux and Lastrapes (1990a) include daily trading volume as an exogenous variable into the ARCH model in explaining the variance of daily returns for the 50 largest companies in the United Kingdom. Their results show that including trading volume ceases the ARCH effect on the conditional variance of returns. This suggests that trading volume acts as a proxy for information arrival, providing significant explanatory power on return volatility. Using a mixture model that accounts for the serial correlation between volume and volatility of return, Lamoureux, and Lastrapes (1994) relax the assumption of the exogenous amount. When serial dependence on information arrival process is taken into consideration, their results show that incorporating trading volume cannot eliminate the volatility persistence of stock returns.

To reduce the number of parameters in the mixture-of-distributions model for stock prices, Richardson and Smith (1994) impose restrictions on parameters in the joint moments of price changes and trading volumes under the conditional normality. They further propose a direct test of the MDH under weak assumptions on the daily flow of information to the market. To conduct the analysis, they use the generalised method of moments (GMM) to estimate characteristics of the random distribution of unobservable information flow. They find that small coefficient of variation, positive skewness, large kurtosis and lognormal distribution can fit the data well. In the subsequent study, Sharma et al. (1996) find that the inclusion of volume into the conditional variance equation can explain the GARCH effects in stock returns, but it cannot eliminate such effects.

The MDH holds when the trading volume has little additional explanatory power for the subsequent price changes. However, this is somehow different as compared to Lucey's finding (2005) based on 52 stocks during 2000-2003 in the context of the Irish stock exchange. The author's finding provides the evidence that is weakly in favour of the MDH, suggesting that trading volume does not appear to be important in explaining the volatility of the Irish market. By using the firm-level data for the 20 most substantial Fortune 500 stocks, Carroll and Kearney (2012) estimate three GARCH model specifications without trading volume and the other three model specifications with trading volume. Their results indicate that contemporaneous trading volume significantly reduces and eliminates the persistence of GARCH effects for return. In this vein, they claim that the MDH holds in most cases.

Lastly, the fourth line of explanation about the contemporaneous relationship between price and trading volume can be taken from the perspective of a possible information arrival process with long memory characteristics. For instance, in examining the behaviour of trading volumes and volatilities among the selected firms from the Standard \& Poor's 100, Bollerslev and Jubinski (1999) use multivariate spectral methods to describe the long-run temporal dependencies in 
volume and volatility. Their results demonstrate that a fractionally integrated process well describes such characteristics of both series and produces long-run hyperbolic decay rate for each volume-volatility. This suggests that high commonality in the degree of fractional integration for each pair is consistent with the stylized MDH model.

Another study that supports such a finding is the application of the robust semi-parametric procedures by Lobato and Velasco (2000), where they find that volatility and volume for thirty stocks in the Dow Jones Industrial Average index exhibit the same degree of extended memory. In contrast, with the use of the model that allows for power transformations of both series, Ané and Ureche-Rangau (2008) find a high degree of intermittency in the volatility of return and volume dynamic appears to be much smoother among fifty 'blue-chip' stocks quoted on the London Stock Exchange. Their findings of universal short-term movement and fundamentally different long-run behaviour of both series provide the rejection of MDH.

However, a search of commodity futures markets that supports the MDH turns up remarkably little in the literature. For instance, Foster (1995) uses the GMM technique to model the contemporaneous relationship between volume and volatility in the case of Brent and WTI crude oil futures markets. Based on daily data of 1990-1994, his results show that both trading volume and return volatilities are contemporaneously related, supporting the MDH. However, although the same information drives both series, the results do not provide strong evidence to indicate that trading volume is an adequate proxy for the rate of information flow.

For copper, aluminium, soybean and wheat futures markets in China, Chen et al. (2004) perform correlation analysis and Granger causality test. Their finding based on daily data of 1996-2002 shows that absolute return and trading volume in these markets are contemporaneously correlated. Biswas and Rajib (2011) find that this contemporaneous correlation happens in Indian gold, silver, and crude oil futures markets during 2005-2009.

To investigate the information arrival hypothesis in the Malaysian CPO futures market, Go and Lau (2016) use a non-linear approach based on cross-correlation functions. They use daily data of 1986-2010 and find that dependence causality in the conditional variance happens from the current return to future volume with different signs of correlation between price and volume series. Their finding of price-volume interaction indicates that volatility of volume is not a proxy for information flow due to the presence of noise traders. This finding is further supported by Go and Lau (2020) who take the 2008/09 global financial crisis (GFC) into account. They find that volatility persistence in post-GFC is higher than Pre-GFC. The volatility of trading volume in post-GFC requires a more extended period to Granger cause volatility of return. This increases volatility persistence, thereby reducing the level of informational efficiency. This finding supports the "heterogeneity of traders" hypothesis, suggesting that market participants are more risk-averse after the crisis.

This narrow focus can limit our understanding of different aspects of participants' reactions in the context of commodity markets. It is worth to examine the true extent of MDH in futures markets for perishable commodities through the conditional variance specification with different assumptions of the error distribution. This is our emphasis in the case of CPO to close the research gap.

\section{DATA}

Daily data comprise price (Malaysian ringgit per metric ton and trading volume (metric ton of 3-month CPO futures contracts over January 2000 - April 2017. These data are extracted from Bursa Malaysia and Thomson Datastream, the first difference is used to transform the futures price into return using natural logarithm at time $t\left(R_{-} t\right)$. Daily trading volume is converted into natural $\operatorname{logarithm}\left(\mathrm{V}_{-} \mathrm{t}\right)$. Given the more extended period, there is a higher probability of existing structural shifts in the return movement. Indeed, it is known that model specifications without considering structural breaks tend to overestimate volatility persistence (Lamoureux and Lastrapes, 1990b). To provide a visual representation of possible structural 
breaks, daily CPO futures returns and trading volume from January 2000 to April 2017 are plotted in Figure 1.

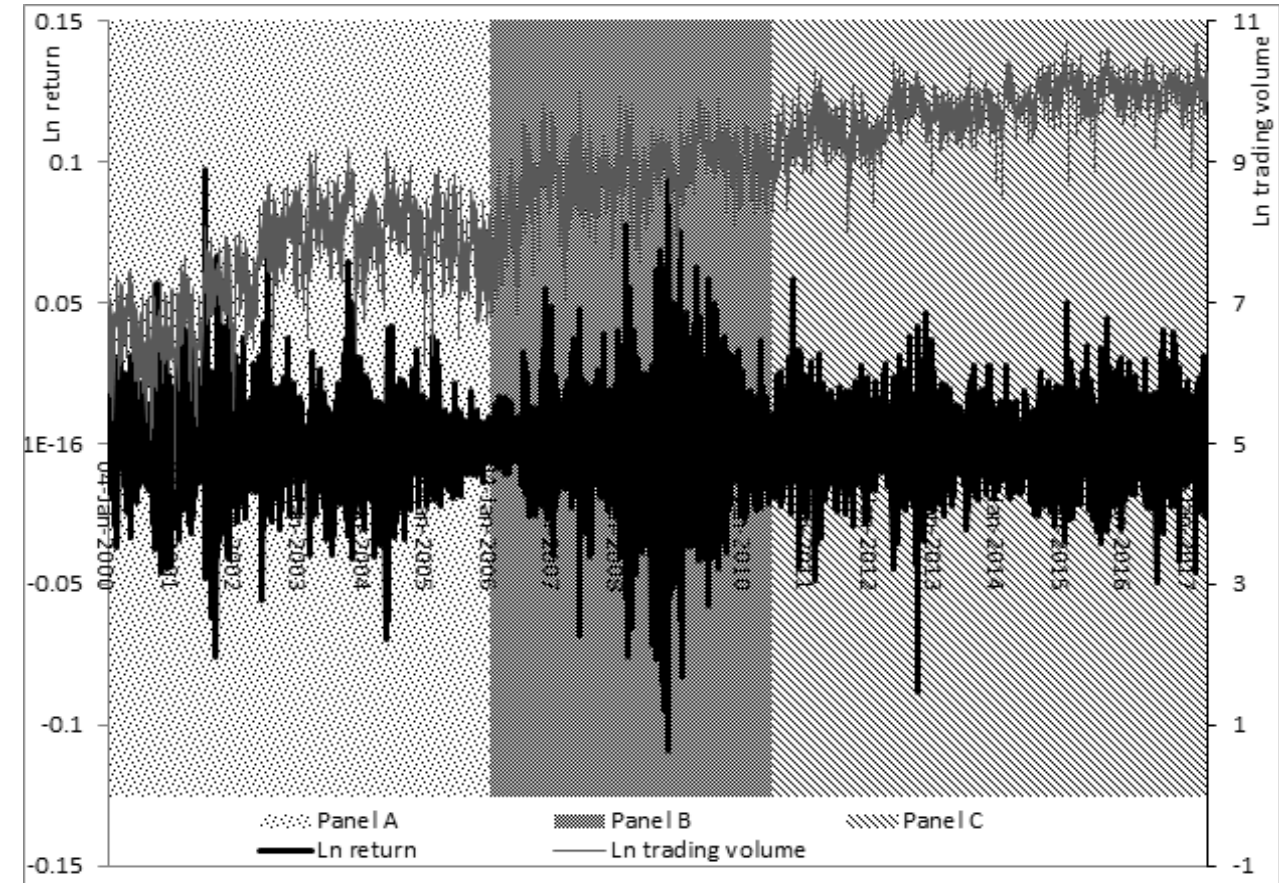

Figure 1: Daily return and trading volume for CPO futures market, January 2000 - April 2017

Figure 1 illustrates the corresponding daily return and trading volume for the CPO futures market, where on the left axis is related to returns and those on the right is related to trading volumes. Through optical observation of graphed data for trading volume, it is clear that an apparent upward trend is visible with a significant variation during the whole sample period. This variation in a trading activity appears to be more prone to speculative activities.

For the futures return, three notable structural changes are present in its movement. The first structural change occurred from January 4, 2000 to January 13, 2006. This structural change was marked by relatively high volatility at the beginning of sample period. However, the volatility declined markedly following the implementation of the Malaysian National Biofuel Policy since January 13, 2006 that promotes the commercialization. The next structural change occurred from January 16, 2006 to June 18, 2010. There were several spikes in its movement between 2007 and 2010 associated with the 2008/09 global financial crisis (GFC). The fluctuation started to decrease from June 18, 2010 onwards, signaling the end of the GFC. The last structural change occurred from June 18, 2010 to April 28, 2017, indicating that the movement of CPO futures return was more stable towards the end of the sample period. Overall, this observation shows there is an extremely strong persistence in variance of $\mathrm{CPO}$ futures returns.

To avoid the spurious appurtenance of persistence in variance, the sample period is separated into several sub-periods according to the above three main structural changes of CPO futures returns. Each sub-period would correspond to each structural change of returns. The identified sub-periods are Panel A (January 4, 2000 - January 13, 2006), Panel B (January 16, 2006 June 18, 2010) and Panel C (June 21, 2010 - April 28, 2017). The preliminary glance at tail behaviour is viewed through quantile-quantile $(\mathrm{Q}-\mathrm{Q})$ plots as shown in Figure 2.

Panel A: January 4, 2000 - January 13, 2006

Panel B: January 16, 2006 - June 18, 2010

Panel C: June 21, 2010 - April 28, 2017 


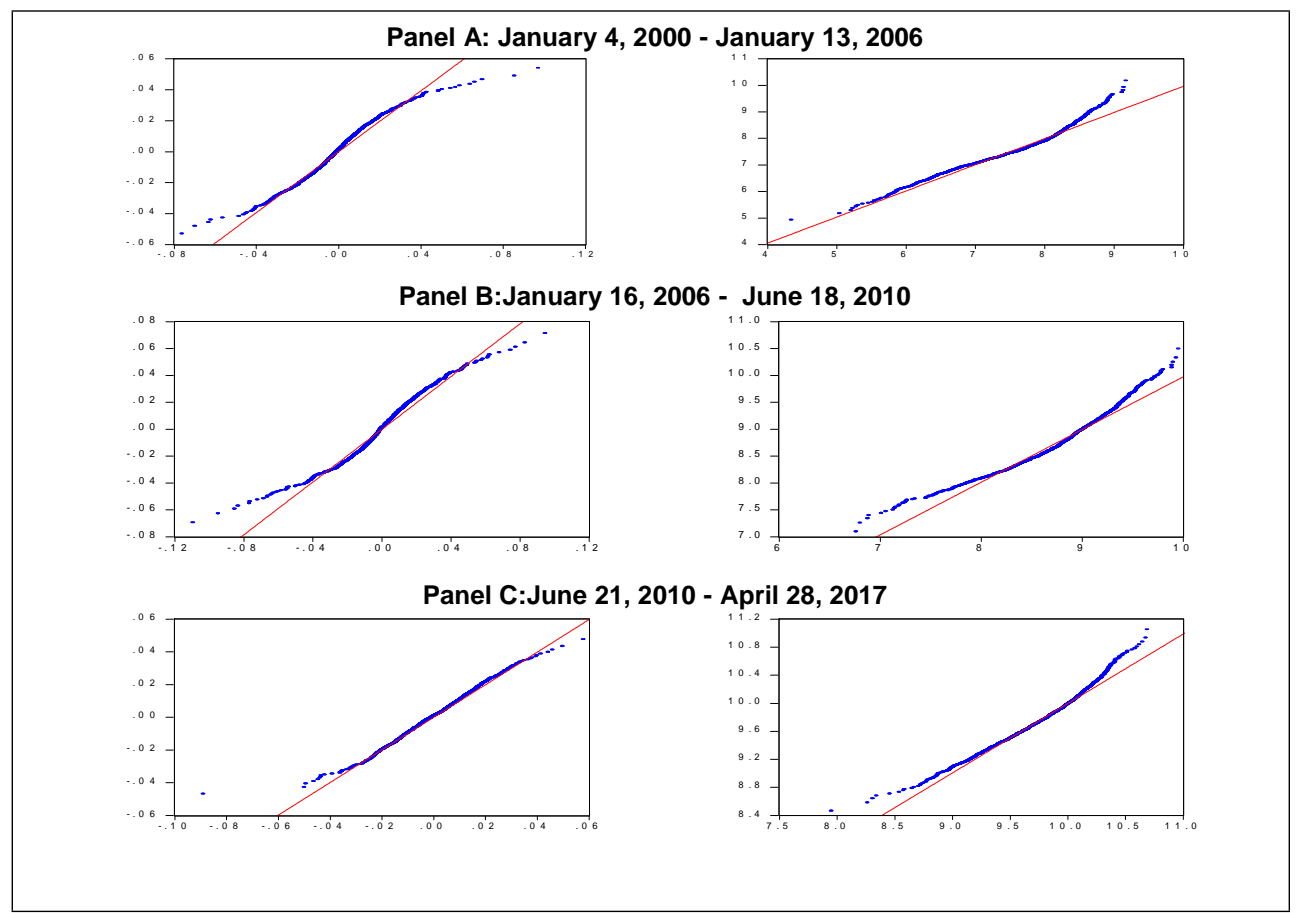

Figure 2: Normal and empirical distributions quantile-quantile plots

For graphical illustration in Figure 2, CPO futures returns for all panels exhibit a non-normal distribution with heavier tails. The lowest outlier is observed in Panel B and Panel C. For the trading volume (Panel A), more outliers are evident at a high end of the range. In Panel $\mathrm{B}$ and Panel C, the outliers are visible at lower left and upper right corners. These outliers of the trading volume are above the line, indicating that the skewing is to the left.

4.1. Descriptive statistics. Table 2 provides the summary statistics that includes the skewness, kurtosis, Jarque-Bera (JB) test for normality, Ljung-Box Q-test for autocorrelation of squared residuals (Q2) and augmented Dickey-Fuller (ADF) test for a unit root. The JB test confirms that a daily CPO futures return is not normally distributed, showing evidence of skewness and excess kurtosis.

\begin{tabular}{|c|c|c|c|c|c|c|}
\hline \multicolumn{7}{|c|}{ Table 2: Summary statistics } \\
\hline & \multicolumn{2}{|c|}{ Panel A } & \multicolumn{2}{|c|}{ Panel B } & \multicolumn{2}{|c|}{ Panel C } \\
\hline & \multicolumn{2}{|c|}{ January 4,2000 - January 13,20} & \multicolumn{2}{|c|}{ January 16,2006 - June 18,20} & \multicolumn{2}{|c|}{ June $21,2010-$ April 28,2017} \\
\hline & $\mathrm{R}$ & $\mathrm{V}$ & $\mathrm{R}$ & $\mathrm{V}$ & $\mathrm{R}$ & $\mathrm{V}$ \\
\hline Skewness & 0.283 & -0.514 & -0.3226 & -0.8385 & -0.128 & -0.539 \\
\hline Kurtosis & 6.279 & 2.667 & 5.7 & 3.998 & 4.302 & 3.323 \\
\hline Jarque-Bera test & $684.339^{* * *}$ & $72.236^{* * *}$ & $351.618^{* * *}$ & $173.748^{* * *}$ & $123.922 * * *$ & $89.038^{* * *}$ \\
\hline $\mathrm{Q}^{2}(15)$ & $316.12^{* * *}$ & $69.628^{* * *}$ & $756.34^{* * *}$ & $111.4^{* * *}$ & $118.06^{* * *}$ & $24.285^{*}$ \\
\hline Observations & 1483 & 1483 & 1095 & 1095 & 1688 & 1688 \\
\hline \multicolumn{7}{|c|}{ Augmented Dickey-Fuller (ADF) unit root test: } \\
\hline drift & $-38.557 * * *(0)$ & $-3.622 * * *(8)$ & $-34.977 * * *(0)$ & $-5.166 * * *(7)$ & $-39.757 * * *(0)$ & $-5.58 * * *(7)$ \\
\hline drift with trend & $-38.544 * * *(0)$ & $-6.473 * * *(5)$ & $-34.987 * * *(0)$ & $-7.006 * * *(5)$ & $-39.749 * * *(0)$ & $-10.6 * * *(4)$ \\
\hline
\end{tabular}

Notes: $\mathrm{R}$ and $\mathrm{V}$ denote daily futures return trading volume. For the Jarque-Bera test, the null hypothesis states that a series is normally distributed. For Ljung-Box Q-test on the autocorrelation of squared residuals up to 15 lags, the null hypothesis states that the data are not serially correlated. For the ADF test, the null hypothesis states that a series has a unit root. *** denotes the null hypothesis is rejected at the $1 \%$ level. The optimal lag length for ADF unit root testing is reported in ( ).

As observed, a daily return is positively skewed in Panel A, suggesting that risk is rather small in the market. Meanwhile, it is turned to be negatively skewed in Panel B and Panel C 
due to the 2008/09 global financial crisis and the 2014 oil crisis. These events further contribute to extreme deviation in the variance of a series and subsequently lead to a high peak and fat tail. In Panel B, it is observed that returns exhibit high degrees of leptokurtosis and negative skewness. This suggests that market participants face a chance of extremely high losses.

For a daily trading volume, the results for all panels show evidence of a non-normal distribution with a negative skewness. In Panel A, its kurtosis is low (platykurtic). In Panel B and Panel $\mathrm{C}$, the distribution is found to have large leptokurtosis. In all panels, the return is found to have relatively fatter tail than trading volume, suggesting that the movement of return is sensitive towards large and repeatedly occurring events as compared to the movement of trading volume.

Two required features for both series should be emphasised in investigating the usefulness of MDH. The first feature is the existence of autoregressive heteroscedasticity in both series. The Ljung-Box Q-test for autocorrelation of squared residuals is performed up to 15 lags for each set and it indicates that both series are autocorrelated. The square of returns is found to have greater autocorrelations by magnitude and significance than trading volumes. The second feature is the existence of a stationary movement of both series. The ADF unit root test is performed based on two auxiliary models, namely the model with a drift and without trend as well as the model with both drift and trend. In all cases, the results of both models provide the rejection of the null hypothesis of a unit root for both series at the $1 \%$ level, implying that both series display stationarity.

Table 3 lists the events that occur during the sub-periods for Panel A, Panel B and Panel C. These events are related to policy implementation. These events affect the magnitude of CPO futures price changes. In Panel A, the Malaysian government launched policies in 2001. These policies influence CPO production and investors' reactions. Their reactions through hedging strategies frequently change CPO futures price for some time, thereby contributing to a large magnitude of futures price changes from 2000 to 2005.

In Panel B, we observe that several events that relate to the financial crisis and climate increase the magnitude of futures price changes dramatically. As seen in Figure 1, CPO futures returns highly fluctuate during the period of 2007/10 global financial crisis. The occurrence of such a crisis coincides with the declining consumption growth of palm oil. This figure suggests that the declining income level in some developing countries during the crisis cause a reduction in their food consumption on "luxuries" like fat and edible oil-related products. For weather climate, deficient rainfall and drought during El-Nino cause the disruption of harvesting and collecting activities, thereby producing low yields in the future.

Although a further increase in CPO price is recorded at the end of 2010, low CPO production with an increase in export demand leads to a reduction of palm oil stocks. In Panel C, we observe that several events relate to policy implementation. For example, banning palm oil products by the Australian government, reduction of export taxes on palm oil products by the Indonesian government and the rejection of the Environmental Protection Agency in the United States on palm-oil based biodiesel are a few of the challenges.

Overall, there is a sign of changing the conditional variance of returns. CPO futures prices are seen to be more sensitive to financial crisis and climate instead of policy implementation. Climate changes and natural disasters impact the supply and demand for commodities, whereas these phenomena may not have an impact on equities directly.

The tail property cannot be obtained from the perspective of skewness and kurtosis, especially for kurtosis which is difficult to capture by a mathematical model. Therefore, we perform the model estimations under the normality, Student-t and generalised error distributions to obtain the persistence of skewness and high excess kurtosis in the daily returns. 


\begin{tabular}{|c|c|}
\hline \multicolumn{2}{|c|}{ ble 3: Episodes for Malaysian palm oil } \\
\hline Jan 2001 & $\begin{array}{l}\text { Federal Land Development Authority (FELDA) was the largest } \\
\text { upstream player who has contributed to } 17.7 \% \text { of the total } \\
\text { planted area and } 20.6 \% \text { of palm oil produced in Malaysia. } \\
\text { Malaysian Government has approved } 1 \text { million tonnes of the vol- } \\
\text { ume of duty-free CPO export for selected companies exporting } \\
\text { CPO include Austral Enterprises Berhad, Golden Hope Plan- } \\
\text { tations Berhad, Kuala Lumpur Kepong Berhad and IOI Cor- } \\
\text { poration Berhad. }\end{array}$ \\
\hline Dec 2001 & $\begin{array}{l}\text { Malaysia was the world's largest exporter of palm oil, account- } \\
\text { ing for about } 61.1 \% \text { or } 10.62 \text { million tonnes of the total exports } \\
\text { of } 17.37 \text { million tonnes. }\end{array}$ \\
\hline \multicolumn{2}{|c|}{ Panel B: January 16, 2006 - June 18, 2010} \\
\hline Mar 2006 & $\begin{array}{l}\text { The government has launched the National Biofuel Policy (NBP } \\
2006 \text { ) for development of national biodiesel activities. }\end{array}$ \\
\hline Dec 3, 2007- Jan 31, 2008 & Zero export of Malaysian biodiesel. \\
\hline Jan 2007- Dec 2010 & $\begin{array}{l}\text { The consumption growth of palm oil has reduced from } 9.8 \% \text { in } \\
2007 / 08 \text { to } 8.5 \% \text { in } 2008 / 09 \text {. This growth further declined to } \\
4.5 \% \text { in } 2009 / 10 \text {. }\end{array}$ \\
\hline Jul 1, 2008 - Sept 30, 2008 & $\begin{array}{l}\text { Oil returns were strongly correlated with daily returns for most } \\
\text { commodities traded in futures markets due to the financial cri- } \\
\text { sis. }\end{array}$ \\
\hline Nov 11,2008 - Dec 18,2008 & $\begin{array}{l}\text { Palm oil export was dropped from RM13,504 million to RM9, } \\
271 \text { million due to heavy rainfall and lower fresh fruit bunches. }\end{array}$ \\
\hline Oct 3,2008 - Oct 31,2008 & $\begin{array}{l}\text { Oil returns were strongly correlated with daily returns for most } \\
\text { commodities traded in futures markets due to the financial cri- } \\
\text { sis. }\end{array}$ \\
\hline Jan 2008- Dec 2009 & $\begin{array}{l}\text { Palm oil and its derived products have declined from RM65.19 } \\
\text { billion to RM49.59 billion due to lower average price all around. }\end{array}$ \\
\hline Jan 2009 & $\begin{array}{l}\text { Companies in the palm oil industry have been moved to down- } \\
\text { stream. }\end{array}$ \\
\hline Dec 2009 & $\begin{array}{l}\text { BMB entered into the partnership with the Chicago Mercantile } \\
\text { Exchange (CME) Group which led to an acquisition of an equity } \\
\text { interest in Bursa Malaysia Derivatives (BMD) Berhad. The } \\
\text { partnership included the licensing of the settlement prices of } \\
\text { the CPO futures to CME and the trading of BMD Berhad's } \\
\text { product offering through the CME Globex electronic trading } \\
\text { platform. }\end{array}$ \\
\hline Jun 2009 - May 2010 & Palm yields have been reduced during the El-Nino event. \\
\hline Dec 31,2009 & $\begin{array}{l}\text { Total CPO futures contract traded has increased from } 3,003,549 \\
\text { contracts to } 4,008,882 \text { contracts steadily with the rising demand } \\
\text { from both China and India. }\end{array}$ \\
\hline Jan 2010 - Dec 2010 & $\begin{array}{l}\text { Palm oil stocks were reduced from } 2,239,257 \text { tonnes to } 1,615,618 \\
\text { tonnes by } 27.85 \% \text {. This decline was mainly due to lower CPO } \\
\text { production by } 3.3 \% \text { coupled with an increase in export demand } \\
\text { by } 4.9 \% \text {. }\end{array}$ \\
\hline
\end{tabular}




\begin{tabular}{|l|l|}
\hline Panel C:June 21, 2010 - April 28, 2017 \\
\hline Jul 2010- Apr 2011 & Palm yields have been increased during the La-Nina event. \\
\hline Jan 2011- Dec 2011 & $\begin{array}{l}\text { The government of Australia claimed that palm oil produced } \\
\text { unhealthy food-related products. }\end{array}$ \\
\hline Mar 2011 - Dec 2011 & CPO yields rose significantly. \\
\hline Apr 2011 - Jun 2011 & $\begin{array}{l}\text { The sharp improvement in CPO demand coincided with a more } \\
\text { substantial premium for soybean oil than CPO. }\end{array}$ \\
\hline Oct 2011 & $\begin{array}{l}\text { The government of Indonesia has reduced export taxes for re- } \\
\text { spective refined, bleached and deodorised (RBD) palm oil and } \\
\text { RBD palm stearin from 11\% and } 7.5 \% \text { to 5\%. For RBD palm } \\
\text { olein, an export tax was reduced from } 12.5 \% \text { to 7\%. }\end{array}$ \\
\hline Jan 2012 & $\begin{array}{l}\text { The Environmental Protection Agency in the United States re- } \\
\text { jected palm-oil based biodiesel for Renewable Fuels Program } \\
\text { because it failed to meet a requirement in reducing emissions } \\
\text { relative to conventional gasoline by 20\%. }\end{array}$ \\
\hline Dec 2012 & $\begin{array}{l}\text { An imposition of a } 300 \% \text { tax on palm oil, popularly dubbed as } \\
\text { the "Nutella Tax" was gunned down. }\end{array}$ \\
\hline Dec 2013 & $\begin{array}{l}\text { 18.6\% of Malaysian palm oil exports were made up of upstream } \\
\text { products as compared to the 81.4\% of exports comprising up- } \\
\text { stream products. }\end{array}$ \\
\hline Dec 2014 & $\begin{array}{l}\text { Palm oil prices fell by } 6 \% \text { due to high stock and expectation on } \\
\text { low demand for biodiesel. }\end{array}$ \\
\hline
\end{tabular}

Source: Teoh (2002), United Nations Development Program (2009), Central Bank of Malaysia (2009), Malaysian Palm Oil Board (2010,2011), Oil World (2010), Economic Transformation Programme (2013), Bursa Malaysia Derivatives (2014), International Monetary Fund (2015) and World Bank (2015).

\section{Methodology}

5.1. Model specification. Our study uses the autoregressive moving average (ARMA) model to explain the conditional mean of a series and adjust the serial autocorrelation. However, this model is unable to take volatility persistence appropriately into account as the volatility of a series fluctuates over time. To capture the stylized facts in the market, the GARCH models of Engle (1982) and Bollerslev (1986) are used. The detailed empirical specification of the univariate ARMA-GARCH model for returns is constructed as:

$$
\begin{gathered}
R_{t}=a_{0}+\sum_{i=1}^{P 1} a_{i} R_{t-i}+\sum_{i=1}^{P 2} b_{i} \varepsilon_{R, t-i}+\varepsilon_{R, t}, \text { where } \varepsilon_{R, t}=z_{R, t} \sqrt{\sigma_{R, t}^{2}} \\
\sigma_{R, t}^{2}=w+\sum_{i=1}^{P 3} \alpha_{i} \varepsilon_{R, t-i}^{2}+\sum_{i=1}^{P 4} \beta_{i} \sigma_{R, t-i}^{2}
\end{gathered}
$$

where $z_{R, t}$ is the unconditional variance of a daily return at time $t, \sigma_{R, t}^{2}$ is the conditional variance of a daily return at time $t$ and $\varepsilon_{R, t}$ is the unexpected daily return that cannot be predicted based on all information available up to the preceding period.

The symmetric GARCH framework is chosen instead of asymmetric GARCH frameworks due to two reasons. First, the use of asymmetric GARCH model specification such as the exponential GARCH (EGARCH) requires statistical properties of the maximum likelihood estimator which are not available under general conditions, but under highly restrictive and unverifiable sufficient conditions. This lack of an invertibility condition for the shocks underlying the model happens because the condition for asymmetry seems to have been ignored or concentrated on an incorrect condition with no clear explanation from the literature (Chang and McAleer, 2017; Martinet and McAleer, 2018). Second, the GARCH specification can be used to comply with the principle 
of parsimony and provide adequate representation in a manner for most financial time series which is consistent with the stylized facts of conditional volatility.

The correct regularity conditions for Quasi-Maximum Likelihood estimators in Equation (2) to be consistent, reliable and asymptotically normal are $w>0, \alpha_{i}>0$ and $\beta_{i}>0$ and $0<\left(\sum_{i=1}^{P 3} \alpha_{i}+\sum_{i=1}^{P 4} \beta_{i}\right)<1$. These sufficient invertibility conditions allow an estimator for the static parameter vector can be able to estimate the time-varying parameter consistently. As a result, there is a possibility of recovering the true path of the time-varying parameter (Wintenberger, 2013). These established strong consistency, and asymptotic properties of maximum likelihood estimators guarantee the conditional and unconditional variances of a GARCH model to be positive definite and finite, respectively.

Even if similar results of maximum likelihood estimators can be obtained in models with exogenous variables, the existence of simultaneity bias remains as an open question. To solve simultaneity bias in the conditional variance for returns, Harvey (1989) suggests a lagged one of trading volume $\left(V_{t-1}\right)$ should be included to represent a contemporaneous volume which is classified as a mixing variable. The augmented model given by Equation (3)-(4) is so-called as the ARMA-GARCH-X.

$$
\begin{gathered}
R_{t}=a_{0}+\sum_{i=1}^{P 1} a_{i} R_{t-i}+\sum_{i=1}^{P 2} b_{i} \varepsilon_{R, t-i}+\varepsilon_{R, t}, \text { where } \varepsilon_{R, t}=z_{R, t} \sqrt{\sigma_{R, t}^{2}} \\
\sigma_{R, t}^{2}=w+\sum_{i=1}^{P 3} \alpha_{i} \varepsilon_{R, t-i}^{2}+\sum_{i=1}^{P 4} \beta_{i} \sigma_{R, t-i}^{2}+\gamma_{0} V_{t}+\gamma_{1} V_{t-1}
\end{gathered}
$$

Incorporated $V_{t-1}$ as shown in Equation (4) is used to represent a contemporaneous trading volume. Its inclusion is consistent with the MDH if the trading volume is serially correlated with the daily number of information arrival to the market. It is evident from a significant coefficient of $\gamma_{1}$ with a positive sign and no serial correlation problem, as well as a marked reduction in volatility persistence of return. This suggests that trading volume acts as a proxy for information flow to the market and reflects return volatility.

To examine the relationship between return and trading volume in the context of the Malaysian futures market, Lau and Go (2012) and Go and Lau (2016) adopt a conventional GARCH model specification which is based on the normality assumption without considering different regimes of returns. However, their way of examination becomes questionable if returns often appear to be skewed and contain the persistent amount of leptokurtosis across time. To capture such a behaviour, we attempt to seek to what extent the following standardised error distributions can enhance the model adequacy.

5.2. Standardized error distributions

There are three settings for the distribution of standardised error $\left(z_{R, t}\right)$. The first setting of $z_{R, t}$ is drawn from the standardised normal distribution with conditional mean zero and time-invariant variance. Thus, the probability density function for the standardised normal distribution is given by Equation (5).

$$
\begin{gathered}
z_{R, t} \sim \text { i.i.d. } N(0,1) \\
f\left(Z_{R, t}\right)=\frac{1}{\sqrt{2 \pi}} \exp \left(-\frac{z_{R, t}^{2}}{2}\right)
\end{gathered}
$$

Maximum likelihood estimators of the parameters in the GARCH model with the standardised distribution are obtained by maximising the following log-likelihood function as Equation (6). 


$$
L(\psi)=-0.5\left(\ln 2 \pi+\ln \sigma_{R, t}^{2}+\frac{\left(R_{t}-\mu_{R}\right)^{2}}{\sigma_{R, t}^{2}}\right)
$$

where $\Psi\left[a_{0}, a_{i}, b_{i}, c, \alpha_{i}, \beta_{i}, \gamma\right]$ is the vector of parameters to be estimated, and the degree of freedom is $\nu$.

If a stylized fact of returns after accounting for conditional heteroscedasticity with the GARCH model, residuals may be still leptokurtic. This fact is due to misspecification of the error term distribution that may lead to negativity assumptions of GARCH process or/and explosive volatility in any estimation. To capture more degree of leptokurtosis, Blattberg and Gonedes (1974) specify the Student- $t$ distribution with $\nu>2$ degrees of freedom. In particular, a $t$-distribution with any degrees of freedom has power tails. A lower value of $\nu$, more extreme the degree of leptokurtosis. Furthermore, the tails of the distribution tapper off at a much slower rate than tails of the normal distribution. To examine return volatility in crude oil markets, Cheong (2009), Marzo and Zagaglia (2010) and Hou and Suardi (2012) use GARCH models with the Student-t distribution.

This distribution is symmetric around zero, where the variance acts as a random variable, but it is fatter than the latter. This symmetric distribution of a random variable with zero mean and unit variance is fatter than the normal distribution. As $\nu$ approaches infinite, the $t$-distribution converges to the normal distribution with $\sigma_{t}^{2}$. Then, the probability density function of standardised errorsis modelled by Equation (7).

$$
\begin{gathered}
z_{R, t} \sim \text { i.i.d. } t(0,1, v) \\
f\left(z_{R, t}\right)=\frac{\Gamma\left(\frac{v+1}{2}\right)}{\sqrt{v \pi} \Gamma\left(\frac{v}{2}\right)}(v-2)^{-1 / 2}\left(h_{t}\right)^{-1 / 2}\left(1+\frac{z_{R, t}^{2}}{\sigma_{R, i}^{2}(v-2)}\right)^{-\frac{v+1}{2}}
\end{gathered}
$$

where $\Gamma(\cdot)$ is the gamma function.

Let $T$ be an independent and identical standard Student-t distribution. The Student- $t$ distribution is obtained if the variance of normal follows an inverted gamma distribution. The log-likelihood function of GARCH models with the Student- $t$ distribution is written as Equation (8).

$$
L(\psi)=T \ln \left[\frac{\Gamma\left(\frac{(v+1)}{2}\right)}{\sqrt{\pi} \cdot \Gamma\left(\frac{v}{2}\right) \cdot \sqrt{v-2}}\right]-\frac{1}{2} \cdot \sum_{t=1}^{T} \ln \sigma_{R, t}^{2}-\frac{v+1}{2} \cdot \sum_{t=1}^{T} \ln \left[1+\left(\frac{z_{R, t}^{2}}{\sigma_{R, t}^{2}(v-2)}\right)\right]
$$

Since returns exhibit fatter or thinner tails than the normal density in most cases, there will be a possible violation of the normality assumption of the error term. To capture a series which is non-normally distributed, Box and Tiao (1973) specify the generalised error distribution (GED). In modelling a GARCH effect, Nelson (1991) is found to consider such an error distribution. Then, it is followed by Zhong et al. (2004) who use exponential GARCH models with a similar distribution to examine volatility for futures trading of the Mexican Price and Quotations Index. For a random variable to have a GED with zero mean, constant variance and the tail parameter of $\mathrm{v}$, such a variable must satisfy the following probability density function as shown in Equation (9).

$$
\begin{gathered}
z_{R, t} \sim i . i . . t(G E D) \\
f\left(z_{R, t}\right)=\frac{v \exp \left(\frac{1}{2}\left|\frac{z_{R, t}}{\lambda \sqrt{\sigma_{R, t}^{2}}}\right|^{v}\right)}{\sqrt{\sigma_{R, t}^{2}} \lambda 2^{(2+1 / v)} \Gamma\left(\frac{1}{v}\right)} \text { with } \lambda=\sqrt{\frac{\left[2^{-2 / v} \Gamma(1 / v)\right]}{\Gamma(3 / v)}}, \text { where } v>0
\end{gathered}
$$


When the GED parameter value of $\nu$ is equal to 2 , the probability density function will turn to be a standard normal distribution. When the GED parameter value of $\nu$ is lesser than 2 , the density would have a fatter tail than the normal density. Lastly, the parameter value of $\nu$ which is more than 2 signifies a thinner tail than the normal density. The log-likelihood function of GARCH models with the GED setting is expressed as Equation (10).

$$
L(\psi)=-0.5 \ln \left(\frac{\Gamma\left(\frac{1}{\gamma}\right)^{3}}{\Gamma\left(\frac{3}{\gamma}\right)\left(\frac{\gamma}{2}\right)^{2}}\right)-0.5 \ln \sigma_{R, t}^{2}-\left(\frac{\Gamma\left(\frac{3}{\gamma}\right)\left(y_{t}-X_{t}^{\prime} \theta\right)^{2}}{\sigma_{j, t}^{2} \Gamma\left(\frac{1}{\gamma}\right)}\right)^{\frac{\gamma}{2}}
$$

\section{EMPIRICAL Results}

Table 4, Table 5 and Table 6 present the results of ARMA-GARCH-type estimation for futures returns in Panel A, Panel B and Panel C, respectively. In all panels, returns are found to have significant $\mathrm{ARCH}$ and $\mathrm{GARCH}$ terms along with positive coefficient values. This indicates that a large shock in the return to its current variance increases its future variance, thereby increasing its shock in the subsequent period. The magnitude of $\alpha_{1}$ shows that the impact of unexpected returns on the subsequent volatility, while the coefficient of $\beta_{1}$ shows the tendency for shocks to the conditional variance to persist. By comparing the significance of the coefficients' values for $\alpha_{1}$ and $\beta_{1}$ in all panels, the most substantial impact of unexpected returns to the subsequent conditional variance is found in Panel B (as shown in Table 5). Then, it is followed by Panel A (as shown in Table 4) and Panel C (as shown in Table 6).

In each panel, test statistics for $Q^{2}(15)$ and ARCH-LM indicate that GARCH models are free from serial correlation. Besides, these model specifications also fare well in terms of accounting for heteroscedasticity and changing unconditional or conditional variance in returns. To determine whether the model specification can provide stable estimates, it is necessary to measure the degree of persistence in the conditional variance process by summing coefficients for ARCH and GARCH terms $\left(\alpha_{1}+\beta_{1}\right)$.

As shown in Table 4, the normal and generalised error distributed GARCH-type estimations provide the sum less than unity, meaning that the effect of the volatility process vanishes over time at an exponential rate.

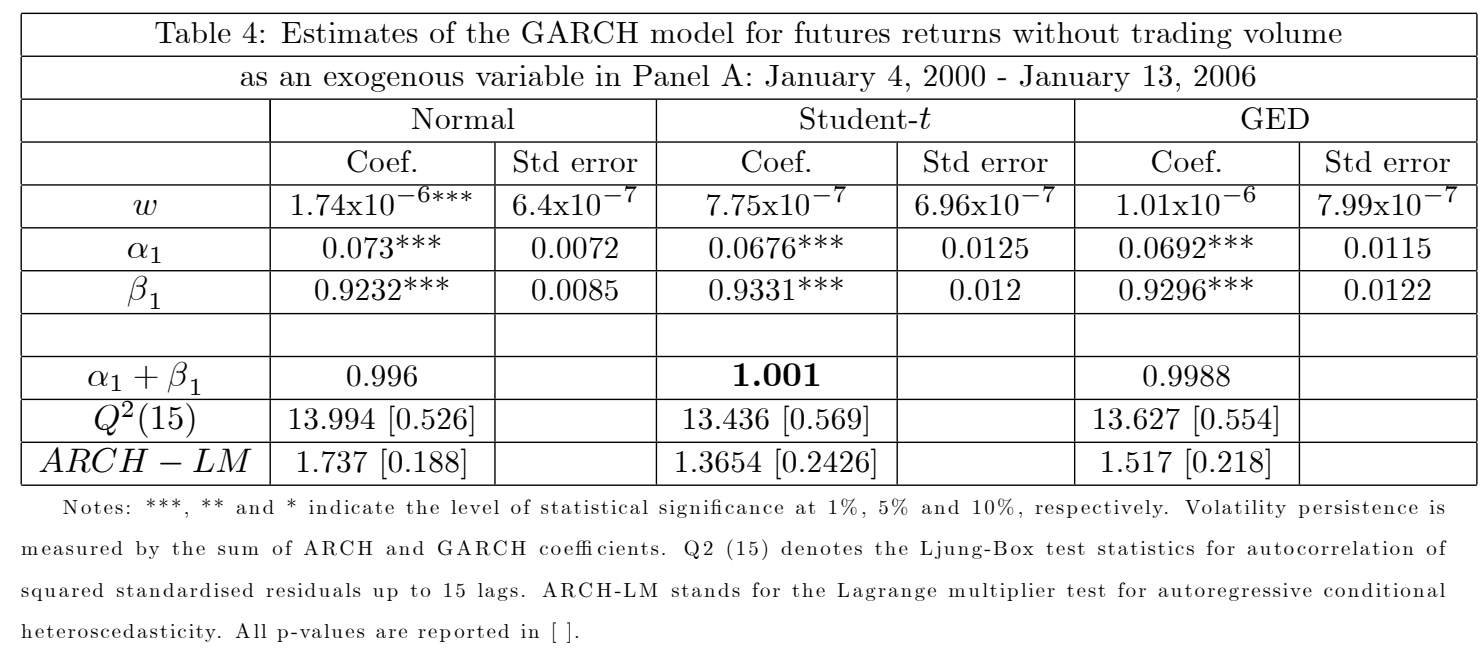

The use of Student-t distributed GARCH-type model does not bring satisfactory results even though ARCH and GARCH coefficients remain significant. This is evidenced by the sum which is more than unity. This may be due to the spillover effects of events in Panel A that have a more powerful effect in the near future than the distant one, thus making a return distribution unable to portray the fat tail syndrome. Under misspecification of the distribution, 
the estimation would display explosive variance. In Table 5 , the explosive variance that is often obtained with the GARCH-type estimations might result from the impact of memory actually increasing over time rather than slowly fading. This apparent persistence in return volatility leads to extreme deviation in the movement of returns as observed in Figure 1. This suggests that return volatility cannot go back to normal levels, especially following the 2008/09 global financial crisis. In Table 6, the GARCH-type estimations under three error distributions show the stationary and persistent impact of shocks. With the stationary persistence of returns, volatility in Panel C (as shown in Table 6) is found to persist relatively lower than the volatility in Panel A (as shown in Table 4).

\begin{tabular}{|c|c|c|c|c|c|c|}
\hline \multicolumn{6}{|c|}{ Table 5: Estimates of the GARCH model for futures returns without trading volume } \\
\hline \multicolumn{3}{|c|}{ as an exogenous variable in Panel B: January 16,2006 - June 18, 2010} \\
\hline & \multicolumn{2}{|c|}{ Normal } & \multicolumn{2}{c|}{ Student- } & \multicolumn{2}{c|}{ GED } \\
\hline & Coef. & Std error & Coef. & Std error & Coef. & Std error \\
\hline$w$ & $1.87 \times 10^{-6 * * *}$ & $6.9 \times 10^{-7}$ & $1.71 \times 10^{-6 * *}$ & $7.39 \times 10^{-7}$ & $1.81 \times 10^{-6 * *}$ & $7.5 \times 10^{-7}$ \\
\hline$\alpha_{1}$ & $0.1041^{* * *}$ & 0.0152 & $0.0989^{* * *}$ & 0.018 & $0.1019^{* * *}$ & 0.0175 \\
\hline$\beta_{1}$ & $0.8973^{* * *}$ & 0.0133 & $0.9024^{* * *}$ & 0.0157 & $0.8993^{* * *}$ & 0.0153 \\
\hline & & & & & & \\
\hline$\alpha_{1}+\beta_{1}$ & $\mathbf{1 . 0 0 1 3}$ & & $\mathbf{1 . 0 0 1 3}$ & & $\mathbf{1 . 0 0 1 2}$ & \\
\hline$Q^{2}(15)$ & $22.79[0.089]$ & & $23.36[0.077]$ & & $22.9[0.09]$ & \\
\hline$A R C H-L M$ & $0.835[0.361]$ & & $0.599[0.439]$ & & $0.734[0.392]$ & \\
\hline
\end{tabular}

Notes: $* * *, * *$ and $*$ indicate the level of statistical significance at $1 \%, 5 \%$ and $10 \%$, respectively. Volatility persistence is measured by the sum of ARCH and GARCH coefficients. Q2 (15) denotes the Ljung-Box test statistics for autocorrelation of squared standardised residuals up to 15 lags. ARCH-LM stands for the Lagrange multiplier test for autoregressive conditional heteroscedasticity. All p-values are reported in [ ].

\begin{tabular}{|c|c|c|c|c|c|c|}
\hline \multicolumn{6}{|c|}{ Table 6: Estimates of the GARCH model for futures returns without trading volume } \\
\hline \multicolumn{6}{|c|}{ as an exogenous variable in Panel C: June 21, 2010 - April 28, 2017 } \\
\hline & \multicolumn{2}{|c|}{ Normal } & \multicolumn{2}{c|}{ Student- $t$} & \multicolumn{2}{c|}{ GED } \\
\hline & Coef. & Std error & Coef. & Std error & Coef. & Std error \\
\hline$w$ & $4.7 \times 10^{-6 * * *}$ & $1.76 \times 10^{-6}$ & $4.45 \times 10^{-6 * *}$ & $1.89 \times 10^{-6}$ & $4.66 \times 10^{-6 * *}$ & $1.82 \times 10^{-6}$ \\
\hline$\alpha_{1}$ & $0.0523^{* * *}$ & 0.0088 & $0.0489^{* * *}$ & 0.0113 & $0.0519^{* * *}$ & 0.0097 \\
\hline$\beta_{1}$ & $0.9235^{* * *}$ & 0.0156 & $0.9279^{* * *}$ & 0.0179 & $0.9241^{* * *}$ & 0.0164 \\
\hline & & & & & & \\
\hline$\alpha_{1}+\beta_{1}$ & 0.9758 & & 0.9768 & & 0.976 & \\
\hline$Q^{2}(15)$ & $8.852[0.885]$ & & $9.0122[0.877]$ & & $8.8608[0.885]$ & \\
\hline$A R C H-L M$ & $0.243[0.622]$ & & $0.4097[0.522]$ & & $0.2581[0.611]$ & \\
\hline
\end{tabular}

Notes: $* * *, * *$ and $*$ indicate the level of statistical significance at $1 \%, 5 \%$ and $10 \%$, respectively. Volatility persistence is measured by the sum of ARCH and GARCH coefficients. Q2 (15) denotes the Ljung-Box test statistics for autocorrelation of squared standardised residuals up to 15 lags. ARCH-LM stands for the Lagrange multiplier test for autoregressive conditional heteroscedasticity. All p-values are reported in [ ].

Table 7, Table 8 and Table 9 present the results of ARMA-GARCH-X model for futures returns in Panel A, Panel B and Panel C, respectively. This model includes a lagged one of trading volume as an exogenous variable in modelling the conditional variance of returns. The adequacy of a model specification is further assessed using the Ljung-Box Q test on squared standardised residuals $\left(\mathrm{Q}^{2}(15)\right)$ and ARCH-LM test. The results show that these augmented models sufficiently explain non-linear sources of variation in returns by adequately accounting a serial correlation of the data in the first and second moments. 


\begin{tabular}{|c|c|c|c|c|c|c|}
\hline \multicolumn{6}{|c|}{ Table 7: Estimates of GARCH-X model for futures returns with a lagged one of trading volume } \\
\hline \multicolumn{7}{|c|}{ as an exogenous variable in Panel A: January 4, 2000 - January 13, 2006 } \\
\hline & \multicolumn{2}{|c|}{ Normal } & \multicolumn{2}{c|}{ Student- $t$} & \multicolumn{3}{c|}{ GED } \\
\hline & Coef. & Std error & Coef. & Std error & Coef. & Std error \\
\hline$w$ & $1.57 \times 10^{-5 * * *}$ & $5.50 \times 10^{-6}$ & $1.01 \times 10^{-5}$ & $1.41 \times 10^{-5}$ & $8.59 \times 10^{-6}$ & $1.41 \times 10^{-5}$ \\
\hline$\alpha_{1}$ & $0.07^{* * *}$ & 0.0079 & $0.0660^{* * *}$ & 0.0132 & $0.0671^{* * *}$ & 0.0123 \\
\hline$\beta_{1}$ & $0.9248^{* * *}$ & 0.0092 & $0.9329^{* * *}$ & 0.0128 & $0.9301^{* * *}$ & 0.013 \\
\hline$\gamma_{1}$ & $-1.81 \times 10^{-6 * * *}$ & $7.04 \times 10^{-7}$ & $-2.10 \times 10^{-6 * *}$ & $1.04 \times 10^{-6}$ & $-1.96 \times 10^{-6 *}$ & $1.02 \times 10^{-6}$ \\
\hline & & & & & & \\
\hline$\alpha_{1}+\beta_{1}$ & 0.9948 & & 0.999 & & 0.9972 & \\
\hline$Q^{2}(15)$ & $15.099[0.444]$ & & $14.89[0.459]$ & & $14.92[0.458]$ & \\
\hline$A R C H-L M$ & $2.176[0.140]$ & & $1.995[0.1578]$ & & $2.07[0.150]$ & \\
\hline
\end{tabular}

Notes: $* * *, *$ and $*$ indicate the level of statistical significance at $1 \%, 5 \%$ and $10 \%$, respectively. Volatility persistence is measured by the sum of ARCH and GARCH coefficients. Q2 (15) denotes the Ljung-Box test statistics for autocorrelation of squared standardised residuals up to 15 lags. ARCH-LM stands for the Lagrange multiplier test for autoregressive conditional heteroscedasticity. All p-values are reported in [ ].

Table 8: Estimates of GARCH-X model for futures returns with contemporaneous and lagged trading volumes as exogenous variables in Panel B: January 16, 2006 - June 18, 2010

\begin{tabular}{|c|c|c|c|c|c|c|}
\hline \multicolumn{6}{|c|}{ trading volumes as exogenous variables in Panel B: January 16, 2006 - June 18, 2010} \\
\hline & \multicolumn{2}{|c|}{ Normal } & \multicolumn{2}{c|}{ Student- $t$} & \multicolumn{2}{c|}{ GED } \\
\hline & Coef. & Std error & Coef. & Std error & Coef. & Std error \\
\hline$w$ & $8.597 \times 10^{-6}$ & $1.41 \times 10^{-5}$ & $1.69 \times 10^{-6 * *}$ & $8.24 \times 10^{-6}$ & $1.61 \times 10^{-5 * *}$ & $8.05 \times 10^{-6}$ \\
\hline$\alpha_{1}$ & $0.0991^{* * *}$ & 0.0174 & $0.0965^{* * *}$ & 0.0179 & $0.0991^{* * *}$ & 0.0174 \\
\hline$\beta_{1}$ & $0.9006^{* * *}$ & 0.0167 & $0.9042^{* * *}$ & 0.0171 & $0.9006^{* * *}$ & 0.0167 \\
\hline$\gamma_{0}$ & $2.40 \times 10^{-5 * * *}$ & $6.01 \times 10^{-6}$ & $2.36 \times 10^{-5 * * *}$ & $6.03 \times 10^{-6}$ & $2.40 \times 10^{-5 * * *}$ & $6.01 \times 10^{-6}$ \\
\hline$\gamma_{1}$ & $-2.5 \times 10^{-5 * * *}$ & $6.96 \times 10^{-6}$ & $-2.5 \times 10^{-5 * *}$ & $6.96 \times 10^{-6}$ & $-2.5 \times 10^{-5 * * *}$ & $6.96 \times 10^{-6}$ \\
\hline & & & & & & \\
\hline$\alpha_{1}+\beta_{1}$ & 0.9997 & & $\mathbf{1 . 0 0 1}$ & & 0.9997 & \\
\hline$Q^{2}(15)$ & $17.910[0.267]$ & & $18.243[0.250]$ & & $17.91[0.267]$ & \\
\hline$A R C H-L M$ & $0.658[0.417]$ & & $0.553[0.457]$ & & $0.658[0.417]$ & \\
\hline
\end{tabular}

Notes: $* * *, * *$ and $*$ indicate the level of statistical significance at $1 \%, 5 \%$ and $10 \%$, respectively. Volatility persistence is measured by the sum of ARCH and GARCH coefficients. Q2 (15) denotes the Ljung-Box test statistics for autocorrelation of squared standardised residuals up to 15 lags. ARCH-LM stands for the Lagrange multiplier test for autoregressive conditional heteroscedasticity. All p-values are reported in [ ].

\begin{tabular}{|c|c|c|c|c|c|c|}
\hline \multicolumn{6}{|c|}{ Table 9: Estimates of GARCH-X model for futures returns with a lagged one of trading } \\
\hline \multicolumn{6}{|c|}{ volumeas an exogenous variable in Panel C: June 21, 2010 - April 28, 2017 } \\
\hline & \multicolumn{2}{|c|}{ Normal } & \multicolumn{2}{c|}{ Student- $t$} & \multicolumn{2}{c|}{ GED } \\
\hline & Coef. & Std error & Coef. & Std error & Coef. & Std error \\
\hline$w$ & $7.54 \times 10^{-7}$ & $1.37 \times 10^{-5}$ & $4.60 \times 10^{-7}$ & $1.56 \times 10^{-5}$ & $7.06 \times 10^{-7}$ & $1.42 \times 10^{-5}$ \\
\hline$\alpha_{1}$ & $0.0524^{* * *}$ & 0.0089 & $0.0489^{* * *}$ & 0.0114 & $0.0519^{* * *}$ & 0.0098 \\
\hline$\beta_{1}$ & $0.9225^{* * *}$ & 0.0158 & $0.9271^{* * *}$ & 0.0181 & $0.9232^{* * *}$ & 0.0166 \\
\hline$\gamma_{1}$ & $4.21 \times 10^{-7}$ & $1.47 \times 10^{-6}$ & $4.25 \times 10^{-7}$ & $1.63 \times 10^{-6}$ & $4.22 \times 10^{-7}$ & $1.47 \times 10^{-6}$ \\
\hline & & & & & & \\
\hline$\alpha_{1}+\beta_{1}$ & 0.9749 & & 0.976 & & 0.9751 & \\
\hline$Q^{2}(15)$ & $8.9599[0.88]$ & & $9.122[0.871]$ & & $8.969[0.879]$ & \\
\hline$A R C H-L M$ & $0.203[0.652]$ & & $0.3595[0.549]$ & & $0.217[0.641]$ & \\
\hline
\end{tabular}

Notes: $* * * * *$ and $*$ indicate the level of statistical significance at $1 \%, 5 \%$ and $10 \%$, respectively. Volatility persistence is measured by the sum of ARCH and GARCH coefficients. Q2 (15) denotes the Ljung-Box test statistics for autocorrelation of squared standardised residuals up to 15 lags. ARCH-LM stands for the Lagrange multiplier test for autoregressive conditional heteroscedasticity. All p-values are reported in [ ]. 
In Table 7, the inclusion of a lagged one of trading volume is found to be significant along with both significant ARCH and GARCH terms. This shows the existence of volatility persistence in the CPO futures returns. In Table 8, incorporating a lagged one of trading volumes is found to bias the regularity and non-negative condition, providing the negative value of an intercept term. To guarantee the existence of the conditional variance with the positive value of an intercept term, a contemporaneous trading volume is suitable to be inserted into the conditional variance equation (Lucey, 2005; Carroll and Kearney, 2012). Under an assumption of all error distributions, the coefficients of $\gamma_{0}$ are statistically significant at the $1 \%$ level with positive values, providing that evidence of a positive contemporaneous relationship between return and trading volume. Apart from this relationship, changes in trading volume would contribute to significant information in reflecting the return movement in the future. In Table 9 , incorporating a lagged one of trading volume in the conditional variance of returns is found to be insignificant along with significant ARCH and GARCH terms. This is due to the movement of trading volumes does not systematically correspond to returns. When analysing the subperiod in Panel A and Panel C, a contemporaneous trading volume is not incorporated into the analysis to comprehend the model specification in line with the principle of parsimony.

For more insights about the role of trading volume, we compare the robustness of a univariate model with an augmented model. The results of estimated GARCH and GARCH-X models for futures returns are summarised in Table 10. As observed in Panel A, the normaland generalised error distributed-GARCH models are well specified regardless of the existence of trading volume as an exogenous variable. The underlying distribution for $\mathrm{CPO}$ futures returns is thicker than the normal distribution given that the GED parameter is 1.384. The inclusion of trading volume into the GARCH model slightly increases the value of a significant estimated GED parameter to be 1.3853. This suggests that an included trading volume under a GED distribution is adequate to capture the fat-tails in futures returns. Conversely, ignoring the effect of trading volumes on returns would lead to slight overestimation on volatility persistence of returns.

\begin{tabular}{|c|c|c|c|c|c|c|c|c|c|c|}
\hline & \multicolumn{5}{|c|}{ Model without an exogenous variable } & \multicolumn{5}{|c|}{ Model with an exogenous variable } \\
\hline & $\mathrm{ARCH}$ & GARCH & $\nu$ & GED & Volatility & $\mathrm{ARCH}$ & GARCH & $\nu$ & GED & Volatility \\
\hline & & & & parameter & persistence & & & & parameter & persistence \\
\hline \multicolumn{11}{|c|}{ Panel A: January 4, 2000 - January 13,2006} \\
\hline Normal & $* * *$ & $* * *$ & - & - & 0.996 & $* * *$ & $* * *$ & - & $-\mathrm{ve}^{* * *}$ & 0.9948 \\
\hline Student- $t$ & $* * *$ & $* * *$ & $6.4^{* * *}$ & - & 1.001 & $* * *$ & $* * *$ & $6.33^{* * *}$ & $-\mathrm{ve}^{* *}$ & 0.999 \\
\hline GED & $* * *$ & $* * *$ & - & $1.384^{* * *}$ & 0.9988 & $* * *$ & $* * *$ & - & $-\mathrm{ve}^{*}$ & 0.9972 \\
\hline \multicolumn{11}{|c|}{ Panel B: January 16, 2006 - June 18,2010} \\
\hline Normal & $* * *$ & $* * *$ & - & - & 1.0013 & $* * *$ & $* * *$ & - & $+\mathrm{ve}^{* * *}$ & 0.997 \\
\hline Student- $t$ & $* * *$ & $* * *$ & $15.56^{* *}$ & - & 1.0013 & $* * *$ & $* * *$ & $18.66^{* *}$ & $+\mathrm{ve}^{* * *}$ & 1.001 \\
\hline GED & $* * *$ & $* * *$ & - & $1.758 * * *$ & 1.0012 & $* * *$ & $* * *$ & - & $+\mathrm{ve}^{* * *}$ & 0.9997 \\
\hline \multicolumn{11}{|c|}{ Panel C:June 21, 2010 - April 28, 2017} \\
\hline Normal & $* * *$ & $* * *$ & - & - & 0.9758 & $* * *$ & $* * *$ & - & + ve & 0.9749 \\
\hline Student- $t$ & $* * *$ & $* * *$ & $22.7^{* * *}$ & - & 0.9768 & $* * *$ & $* * *$ & 22.704 & $+\mathrm{ve}$ & 0.976 \\
\hline GED & $* * *$ & *** & - & $1.932^{* * *}$ & 0.976 & $* * *$ & *** & - & $+\mathrm{ve}$ & 0.9751 \\
\hline
\end{tabular}

Notes: "Sign" denotes the sign of coefficient for trading volume. V stands for degrees of freedom for the Student- t distribution. $* * *, * *$ and $*$ indicate that the level of statistical significance at $1 \%, 5 \%$ and $10 \%$, respectively. Volatility persistence is measured by the sum of ARCH and GARCH coefficients.

Surprisingly, the Student- $t$ distributed-GARCH model without considering the effect of trading volume on returns is not well specified because it provides explosive variance (persistence level of 1.001). Inclusion of trading volume into the conditional variance of returns is able to improve model specification, based on the level of stable persistence (0.999). This inclusion slightly reduces the significant estimated parameter of $\nu$ from 6.4 to 6.33. The Student- $t$ 
distributed-GARCH model with an augmented trading volume as an exogenous variable is found. To capture leptokurtosis with positive skewness in CPO futures returns appropriately. The presence of such a variable in the model can produce stable estimates and appear to be useful in risk forecasts, especially for risk-averse participants.

Nevertheless, the model that consists of trading volume performs slightly better, where its results do indicate the lagged term of trading volume negatively influences the conditional volatility of returns. An essential attribute of such an effect is the existing traders with a higher degree of informed trading. As observed in Figure 1, an increasing trading volume in the $\mathrm{CPO}$ futures market is due to the fact that Malaysia exports the substantial amount of palm oil in the world that generally boosts liquidity. This is a symptom of the fact that the market is dominated by liquidity traders who consider others to be less well-informed than they are. With such overconfidence, they tend to underreact to the information contained in the trading decisions of others, thereby reducing volatility.

In Panel B, it is shown that the parameter estimates in the standard GARCH models under three distributions are unstable as the sum between coefficients of ARCH and GARCH terms exceeds one. Under the standard and generalised error distributions, the inclusion of contemporaneous and lagged trading volumes into the conditional variance equation marginally reduces the degree of persistence of returns to be stable, as well as slightly increases the value of significant GED parameter from 1.7584 to 1.806 . This suggests that the absence of trading volume would lead to an overestimation of volatility persistence.

Under the Student- $t$ distribution, a relatively sizeable estimated v of 15.56 implies that the leptokurtosis of the conditional distribution does not account for a significant amount of residual leptokurtosis, thereby leading to unstable parameter estimates. This implies explosive volatility dynamics or simply a poorly fitting model. Including both contemporaneous and lagged trading volumes into the model, explosive variance still turns out as compared to those obtained from the GARCH model estimation even if there is a slight reduction of degrees of persistence. This can be demonstrated by the increase of the estimated $\mathrm{v}$ from 15.56 to 18.66 , implying that the existence of a fat tail for returns. Since returns exhibit high excess kurtosis and negative skewness as shown in Table 2, including an exogenous variable into the Student-t distributedGARCH model still cannot allow parameter estimates to do a better job of capturing volatility dynamics of returns.

However, including trading volume as an exogenous variable into the normaland generalised error distributed-GARCH models provides a significant positive effect on the conditional volatility of returns. This effect indicates that an increasing trading volume leads to more available information in the market. However, trading volume cannot wipe out the volatility persistence of returns since its inclusion in the model still provides significant ARCH and GARCH effects. This evidence of a slight reduction in volatility persistence of returns is weakly in favour of the $\mathrm{MDH}$, indicating that trading volume adds little to the information which is already discounted in CPO futures prices. Furthermore, the CPO futures market mostly stays in backwardation instead of contango. To "overreact" to the new arrival of information, investors frequently predict futures prices instead of trading volumes to hedge their risk by deciding a particular position in the market (Go and Lau, 2017). In turn, trading volume still plays a role as an explicative variable which is a vital source of conditional heteroscedasticity.

As shown in Table 10, the GARCH model estimation in Panel $\mathrm{C}$ under three distributional assumptions shows that the volatility persistence of returns is slightly reduced after incorporating the lagged of trading volume. However, such a lagged variable does not contribute to any impact on the conditional variance of returns. As a result, the significant value for GED parameter remains as 1.9321 .

Overall, the degree of leptokurtosis observed in CPO futures returns is typically much greater than what can be accounted for simply through the observed heteroscedasticity. However, the conditional heteroscedasticity could not account for some portion of observed leptokurtosis in the return. For the GARCH model with an exogenous variable, it is found that the presence 
of trading volume in the model with conditional Student- $t$ distributed errors could account for portion of observed leptokurtosis in the return. Such a distributional assumption is better to model CPO futures returns that exhibit high degree of leptokurtosis and positive skewness.

\section{Conclusions and Implications}

The purpose of this study is to examine the role of trading volume in driving information transmission channels for $\mathrm{CPO}$ futures returns. If trading volume could play such a role, it is able to account for the uneven flow of information to explain the presence of GARCH effect in the CPO futures return. Three structural regimes with different degrees of asymmetric distribution are identified in the movement of returns over January 2000 - April 2017. In each regime, the extent of response from trading volume to the arrival of new information in the $\mathrm{CPO}$ futures market is examined using the ARMA-GARCH-X model, in which the residuals follow the normal Student-t and generalised error distributions.

Based on the models, our results provide three notable findings: First, the inclusion of trading volume reduces volatility persistence of CPO futures returns in Panel A and B, causing the weak reaction of conditional variance to shocks. This finding is attributed to relatively low response of futures trading to price sensitivity for which trading volume cannot act as a good proxy for information flow; Second, the presence of trading volume as an exogenous variable in the model is found to be important for obtaining the goodness of fit for efficient estimates; Third, we explore the impact of distributional assumptions on the model fitting process for CPO futures returns with the inclusion of trading volume. When modelling the CPO futures return that exhibits high degree of leptokurtosis and positive skewness, Student-t distributional assumption is found to be an important assumption. By makingsuch an assumption for a modelling purpose could result in a better conclusion yield from a given GARCH-type model as the parameters are able to provide more information of the return.

Although trading volume cannot act as a good proxy for information flow, its presence as an exogenous variable in the GARCH model with conditional Student-t distributed errors could reduce the degree of potential explosiveness. Based on this, two implications are suggested as follows. First, practitioners should rely on the pricing of long-term futures contracts which is a non-trivial function of the current information set to forecast volatility. Indeed, the adverse growing condition of $\mathrm{CPO}$ cannot provide inventories that associate with the long-run supply. The forecasting of futures volatility can give them insights in allocating their inventories optimally for production and investment in CPO related products. For example, they can use the futures volatility as an inflation hedge to assess the quality of prices, as well as a predictor of future CPO prices for investment and hedging decisions.

Second, our study documents whether the inclusion of trading volume into the GARCH modelling could adequately fit the CPO futures returns based on the unobservable information flow. To account stylized facts such as large kurtosis and positive skewness, our finding demonstrates the Student-t distibutional assumption is the most appropriately used conditional distribution in GARCH model with trading volume as an exogenous variable. Therefore, when the CPO futures return has an overreaction to good news instead of bad news, financial analysts are suggested to consider trading volume that can help them in assessing risk and measuring the value-at-risk of their market position.

\section{REFERENCES}

[1] Agnolucci, P. (2009), "Volatility in crude oil futures: A comparison of the predictive ability of GARCH and implied volatility models", Energy Economics, Vol. 31 No. 2, pp. 316-321.

[2] Ané, T. and Ureche-Rangau, L. (2008), "Does trading volume explain stock returns volatility?", Journal of International Financial Markets, Institutions, and Money, No. 18 No. 3, pp. 216-235.

[3] Barberis, N., Shleifer, A. and Vishny, R. (1998), "A model of investor sentiment1", Journal of Financial Economics, Vol. 49 No. 3, pp. 307-343.

[4] Biswas, S. and Rajib, P. (2011), "Testing price-volume relationships for Indian commodity futures", Journal of Indian Business Research, Vol. 3 No.2, pp. 117-131. 
[5] Blattberg, R. C. and Gonedes, N. J. (1974), "A comparison of the stable and student distributions as statistical models for stock prices", Journal of Business, Vol. 47 No.2, pp. 244-280.

[6] Blume, L., Easley, D. and O'hara, M. (1994), "Market statistics and technical analysis: The role of volume", Journal of Finance, Vol. 49 No.1, pp. 153-181.

[7] Bollerslev, T. (1986), "Generalized autoregressive conditional heteroskedasticity", Journal of Econometrics, Vol. 31, No. 3, pp. 307-327.

[8] Bollerslev, T. and Jubinski, D. (1999), "Equity trading volume and volatility: Latent information arrivals and common long-run dependencies". Journal of Business \& Economic Statistics, Vol. 17 No.1, pp. 9-21.

[9] Box, G. E. P. and Tiao, G. C. (1973), "Bayesian inference in statistical analysis". Reading, MA: AddisonWesley.

[10] Bursa Malaysia Derivatives (2014), "Crude palm oil futures (FCPO)", available at: http://www.bursamalaysia.com/market/ derivatives/products/commodity-derivatives/crude-palm-oilfutures-fcpo/ (accessed 30 June 2015).

[11] Carroll, R. and Kearney, C. (2012), "Do trading volumes explain the persistence of GARCH effects?" Applied Financial Economics, Vol. 22 No. 23, pp. 1993-2008.

[12] Central Bank of Malaysia (2009), "Monthly Statistical Bulletin July 2009. Kuala Lumpur: Central Bank", available at: http://www.bnm.gov.my/index.php?ch $=$ en_publication\&pg $=$ en $\_$msb\&ac $=80 \& l a n g=e n \& u c=2$ (accessed 30 June 2015).

[13] Chang, C. L. and McAleer, M. (2017), "The correct regularity condition and interpretation of asymmetry in EGARCH", Economics Letters, Vol. 161, pp. 52-55.

[14] Chen, G., Firth, M. and Xin, Y. (2004), "The price-volume relationship in China's commodity futures markets", Chinese Economy, Vol. 37 No.3, pp. 87-122.

[15] Cheong, C. W. (2009), "Modeling and forecasting crude oil markets using ARCH-type models", Energy Policy, Vol. 37 No.6, pp. 2346-2355.

[16] Choi, K. H., Jiang, Z. H., Kang, S. H. and Yoon, S. M. (2012), "The relationship between trading volume and asymmetric volatility in the Korean stock market", Modern Economy, Vol. 3 No.5, pp. 584-589.

[17] Clark, P. K. (1973), "A subordinated stochastic process model with finite variance for speculative prices", Econometrica, Vol. 41 No. 1, pp. 135-155.

[18] Do, H. X., Brooks, R., Treepongkaruna, S. and Wu, E. (2014), "How does trading volume affect financial return distributions?", International Review of Financial Analysis, Vol. 35, pp. 190-206.

[19] Economic Transformation Programme (2013), "Palm oil and rubber", available at: http://etp.pemandu.gov.my/annualreport2013/upload/07_NKEA05_ENG_POR.pdf(accessed 30 June 2015).

[20] Engle, F. R. (1982), "Autoregressive conditional heteroscedasticity with estimates of the variance of United Kingdom inflation". Econometrica,Vol. 50 No. 4, pp. 987-1007.

[21] Epps, T. W. (1975), "Security price changes and transaction volumes: Theory and evidence", American Economic Review, Vol. 65 No.4, pp. 586-597.

[22] Epps, T. W. and Epps, M. L. (1976), "The stochastic dependence of security price changes and transaction volumes: Implications for the mixture-of-distributions hypothesis", Econometrica, Vol. 44 No.2, pp. 305321.

[23] Fama, E. F. (1998), "Market efficiency, long-term returns, and behavioural finance1", Journal of Financial Economics, Vol. 49 No.3, pp. 283-306.

[24] Food and Agricultural Organization of the United Nations (2011), "Food price volatility and the right to food. Right to food policy brief No. 1, 2011", available at: http://www.fao.org/fileadmin/templates/righttofood/documents/RTF_publications/EN/issuesbrief_ PRICEvolatility_EN.pdf(accessed 18 June 2016).

[25] Foster, A. J. (1995), "Volume-volatility relationships for crude oil futures markets", Journal of Futures Markets, Vol. 15 No. 8, pp. 929-951.

[26] Go, Y. H. and Lau, W. Y. (2014), "Evaluating the hedging effectiveness in crude palm oil futures market: a bivariate threshold GARCH model", Empirical Economics Letters, Vol. 13 No. 11, pp. 1159-1170.

[27] Go, Y. H. and Lau, W. Y. (2015), "Evaluating the hedging effectiveness in crude palm oil futures market during financial crises". Journal of Asset Management, Vol. 16 No. 1, pp. 52-69.

[28] Go, Y. H. and Lau, W. Y. (2016), "Information arrival between price change and trading volume in crude palm oil future market: A nonlinear approach", Journal of Asian Finance. Economics and Business, Vol. 3 No.3, pp. 79-91.

[29] Go, Y. H. and Lau, W. Y. (2017). "Investor demand, market efficiency and spot-futures relation: Further evidence from crude palm oil", Resources Policy, Vol. 53, pp.135-146.

[30] Go, Y. H. and Lau, W.Y. (2020). "The impact of global financial crisis on informational efficiency: Evidence from price-volume relation in crude palm oil futures market", Journal of Commodity Markets, https://doi.org/10.1016/j.jcomm.2018.10.003 (online first)

[31] González-Rivera, G. and Drost, F. C. (1999), "Efficiency comparisons of maximum-likelihood-based estimators in GARCH models", Journal of Econometrics, Vol. 93 No.1, pp. 93-111. 
[32] Harris, L. (1987), "Transaction data tests of the mixture of distributions hypothesis", Journal of Financial and Quantitative Analysis, Vol. 22 No.2, pp. 127-141.

[33] Harvey, A. C. (1990), "Forecasting, structural time series models, and the Kalman filter", Cambridge University Press, Cambridge.

[34] Hiemstra, C. and Jones, J. D. (1994), "Testing for linear and nonlinear Granger causality in the stock price-volume relation", Journal of Finance, Vol. 49 No. 5, pp. 1639-1664.

[35] Hou, A. and Suardi, S. (2012). "A nonparametric GARCH model of crude oil price return volatility", Energy Economics, Vol. 34 No.2, pp. 618-626.

[36] International Monetary Fund (2015), "Commodity Market Monthly", Washington DC, January 2015, pp.18, available at: https://www.imf.org/external/np/res/commod/pdf/monthly/010115.pdf (accessed 18 June 2016).

[37] Lamoureux, C. G. and Lastrapes, W. D. (1990a), "Heteroskedasticity in stock return data: Volume versus GARCH effects", Journal of Finance, Vol. 45 No.1, pp. 221-229.

[38] Lamoureux, C. G. and Lastrapes, W. D. (1990b), "Persistence in variance, structural change, and the GARCH model", Journal of Business \& Economic Statistics, Vol. 8 No.2, pp. 225-234.

[39] Lamoureux, C. G. and Lastrapes, W. D. (1994), "Endogenous trading volume and momentum in stockreturn volatility", Journal of Business \& Economic Statistics, Vol. 12 No.2, pp. 253-260.

[40] Lau, W. Y. and Go, Y. H. (2012), "Information flow between return and trading volume in Malaysian futures market", African Journal of Business Management, Vol. 6 No. 32, pp. 9326-9334.

[41] Le, V. and Zurbruegg, R. (2010), "The role of trading volume in volatility forecasting", Journal of International Financial Markets, Institutions and Money, Vol. 20 No.5, pp. 533-555.

[42] Liesenfeld, R. (2001), "A generalized bivariate mixture model for stock price volatility and trading volume", Journal of Econometrics, Vol. 104 No. 1, pp. 141-178.

[43] Lobato, I. N. and Velasco, C. (2000), "Long memory in stock-market trading volume". Journal of Business \& Economic Statistics, Vol. 18 No.4, pp. 410-427.

[44] Lucey, B. M. (2005), "Does volume provide information? Evidence from the Irish stock market", Applied Financial Economics Letters, Vol. 1 No. 2, pp. 105-109.

[45] Malaysian Palm Oil Board (2010), "Malaysia Palm Oil Industry Performance 2009", Global Oils \& Fats Business Magazine, Vol. 7 No. 1, pp. 1-11, available at: http://www.mpoc.org.my/gofbm_view.aspx?id=303c1df0-6a15-4eba-9f57-5620fe9a1355(accessed 18 June 2016).

[46] Malaysian Palm Oil Board (2011), "Quarterly report on oils and fats", available at: http://bepi.mpob.gov.my/images/Quarterly2011/4th\%20Quarter\%202011(accessed 30 June 2014).

[47] Malaysian Palm Oil Board (2015), "Annual report 2015", available at http://bepi.mpob.gov.my/images/overview/Overview_of_Industry_2015.pdf (accessed 13 May 2016).

[48] Martinet, G. G. and McAleer, M. (2018). "On the invertibility of EGARCH (p, q)", Econometric Reviews, Vol. 37 No. 8, pp. 824-849.

[49] Marzo, M. and Zagaglia, P. (2010), "Volatility forecasting for crude oil futures", Applied Economics Letters, Vol. 17 No.16, pp. 1587-1599.

[50] Nelson, D. B. (1991), "Conditional heteroskedasticity in asset returns: A new approach", Econometrica: Journal of the Econometric Society, pp. 347-370.

[51] Newey, W. K. and Steigerwald, D. G. (1997), "Asymptotic bias for quasi-maximum-likelihood estimators in conditional heteroskedasticity models", Econometrica: Journal of the Econometric Society, Vol. 65 No. 3 , pp. 587-599.

[52] Oil World (2010), "Oil world statistical update", Hamburg, West Germany, various issues.

[53] Richardson, M. and Smith, T. (1994), "A direct test of the mixture of distributions hypothesis: Measuring the daily flow of information", Journal of Financial and Quantitative Analysis, Vol. 29 No. 1, pp. 101-116.

[54] Sharma, J. L., Mougoue, M. and Kamath, R. (1996), "Heteroscedasticity in stock market indicator return data: volume versus GARCH effects", Applied Financial Economics, Vol. 6 No. 4, pp. 337-342.

[55] Statista (2018), "Consumption of vegetable oils worldwide from 2013/14 to 2017/2018, by oil type (in million metric tons)", available at: https://www.statista.com/statistics/263937/vegetable-oils-globalconsumption/(accessed 26 June 2018).

[56] Suominen, M. (2001), "Trading volume and information revelation in stock markets", Journal of Financial and Quantitative Analysis, Vol. 36 No.4, pp. 545-565.

[57] Tauchen, G. E. and Pitts, M. (1983), "The price variability-volume relationship on speculative markets". Econometrica, Vol. 51 No.2, pp. 485-505.

[58] Teoh, C. H (2002), "The palm oil industry in Malaysia-from seed to the frying pan. Malaysia: Plantation Agriculture", WWF Malaysia, available at: http://assets.panda.org/ downloads/oilpalmchainpartaandb_esri.pdf; 2002 (accessed 30 June 2014).

[59] United Nations Development Program (2009), "The global financial crisis and the Malaysian economy: Impact and response. A Joint Report by the Institute for Strategic and International Studies (ISIS) and the Faculty of Economics and Administration, University of Malaya, Kuala Lumpur, Malaysia, available at 
http://www.isis.org.my/attachments/e-books/The Global Financial Crisis and the Malaysian Economy.pdf (accessed 30 June 2014).

[60] Wintenberger, O. (2013), "Continuous invertibility and stable QML estimation of the EGARCH $(1,1)$ model", Scandinavian Journal of Statistics, Vol. 40 No.4, pp. 846-867.

[61] World Bank (2015), "Commodity Markets Outlook", January 2015, Quarterly Report, pp. 1-29, available at: http://documents.worldbank.org/curated/en/380281468125701579/pdf/938350WP0Box3805a0commodity0 Jan2015.pdf (accessed30 June 2016).

[62] Zhong, M., Darrat, A. F. and Otero, R. (2004), "Price discovery and volatility spillovers in index futures markets: Some evidence from Mexico", Journal of Banking \& Finance, Vol. 28 No. 12, pp. 3037-3054. 